AN APPLICATION OF SPENCER'S METHOD TO THE STIELTJES AND HAMBURGER MOMENT PROBLEMS

JULY 1959

CONTRACT AT-11-1-GEN-14

BETTIS PLANT-PITTSBURGH, PA. OPERATED FOR THE U.S. ATOMIC ENERGY COMMISSION BY BETTIS ATOMIC POWER DIVISION, WESTINGHOUSE ELECTRIC CORPORATION

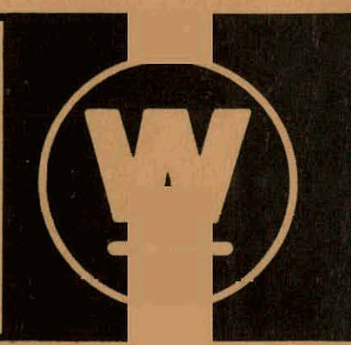




\section{DISCLAIMER}

This report was prepared as an account of work sponsored by an agency of the United States Government. Neither the United States Government nor any agency Thereof, nor any of their employees, makes any warranty, express or implied, or assumes any legal liability or responsibility for the accuracy, completeness, or usefulness of any information, apparatus, product, or process disclosed, or represents that its use would not infringe privately owned rights. Reference herein to any specific commercial product, process, or service by trade name, trademark, manufacturer, or otherwise does not necessarily constitute or imply its endorsement, recommendation, or favoring by the United States Government or any agency thereof. The views and opinions of authors expressed herein do not necessarily state or reflect those of the United States Government or any agency thereof. 


\section{DISCLAIMER}

Portions of this document may be illegible in electronic image products. Images are produced from the best available original document. 


\title{
AN APPLICATION OF SPENCER'S METHOD TO THE STIELTJES AND HAMBURGER MOMENT PROBLEMS
}

W. H. Guilinger

\section{Contract AT-11-1-GEN-14}

July 1959

\author{
Y \\ Price $\$ .75$ \\ Available from the Office of Technical Services, \\ Department of Commerce, \\ Washington 25, D. C.
}

This document is an interim memorandum prepared primarily for internal reference and does not represent a final expression of the opinion of Westinghouse. When this memorondum is distributed externally, it is with the express understanding that Westinghouse makes no representation as to completeness, accuracy, or usability of information contained therein.

\section{BETTIS PLANT - PITTSBURGH, PA. \\ OPERATED FOR THE U.S. ATOMIC ENERGY COMMISSION BY BETTIS ATOMIC POWER DIVISION, WESTINGHOUSE ELECTRIC CORPORATION}




\section{STANDARD EXTERNAL DISTRIBUTION}

No. Copies

616

UC-34: Physics and Mathematics, TID-4500, 14th Edition

\section{SPECIAL EXTERNAL DISTRIBUTION}

Manager, Pittsburgh Naval Reactors Operations Office, AEC

Argonne National Laboratury, W. F. Miller

Brookhaven National Laboratory, J. Chernick

Brookhaven National Laboratory, M. Rose

David Taylor Model Basin, H. Polachek

Ilarvard Univer'sity, G. Birkhoff

Knolls Atomic Power Laboratory, R. Ehrlich

Los Alamos Scientific Laboratory, B. Carlson

New York University, R. Richtmyer

Oak Ridge National Laboratory, A. Householder

University of California Radiation Laboratory, Livermore, S. Fernbach

Westinghouse Research Laboratories, M. Ostrofsky

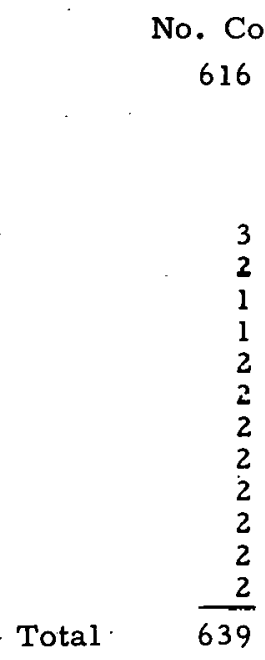

\section{LEGAL NOTICE}

This report was prepared as an account of Government sponsored work. Neither the United States, nor the Commission, nor any person acting on behalf of the Commission:

A. Makes any warranty or representation, expressed or implied, with respect to the accuracy, completeness, or usefulness of the information contained in this report, or that the use of any information, apparatus, method, or process disclosed in this report may not infringe privately owned rights; or

B. Assumes any liabilities with resnerst th the use if, or for damagoo rooulting from the use of any information, apparatus, method, or process disclosed in this report.

As used in the above. "Derson asting on hehalf of tho commiseion" inoludeg any emploje or contractor of the Commission, or employe of such contractor, to the extent that such omploye or contractor of the Coniulissiun, ur employo of such contractor prepares, disseninates, or provides access to, any information pursuant to his employment or contract with the Commission, or his employment with such contractor. 


\section{CONTENTS}

Page No.

THE STIELTJES MOMENT PROBLEM

THE HAMBURGER MOMENT PROBLEM

COMPUTER SOLUTION OF THE STIELTJES MOMFNT PROBLEM

COMPUTER SOLUTION OF THE HAMBURGER MOMENT PROBLEM

NUMERICAL RESULTS

ACKNOWLEDGEMENT

REFERENCES 
Given the moments of a function, it is often desirable to obtain a numerical approximation of the function. A method for estimating the solutions of the Stieltjes and Hamburger moment problems is developed. Calculations included in this report indicate that the method is both feasible and accurate.

\section{AN APPLICATION OF SPENCER'S METHOD TO THE STIELTJES AND HAMBURGER MOMENT PROBLEMS}

\section{Willis $\mathrm{H}$. Guilinger}

For some classes of problems, it is more convenient (or feasible) to obtain the moments of an unknown function than it is to obtain the function itself. As an example, the transport equation for the slowing down of neutrons is commonly solved for a finite number of moments of the slowing down density. In this problem, as in many others, the unknown function is known to be positive and continuous from physical considerations. Thus, it shall be assumed that the unknown function is a positive continuous function.

In the Stieltjes moment problem, the integration (to obtain the moments) ranges from zero to infinity. In the Hamburger moment problem, the integration ranges from minus infinity to plus infinity. Given an even number of moments in either of these problems, along with asymptotic conditions, a positive continuous function will be constructed with those moments and asymptotic conditions. If such a oolution does not exist, then the mements are not from a positive continuous function, indicating a violation of the assumptions. However, the existence of a solution does not imply that the assumptions are valid. Therefore, when this method is used, it should be known from physical considerations that the unknown function is positive and continuous.

In both the Stieltjes and Hamburger moment problems, the proposed method of solution is a modification of Spencer's method (Ref 1).

\section{THE STIELTJES MOMENT PROBLEMI}

Since the original Stieltjes moment problem assumes an infinite number of moments given, a variation is actually being considered. For computational purposes, the restriction to an even number of moments will be made. Thus, given an even number of moments, say $K+1$, of an unknown positive continuous function $f(x), x \geq 0$, where the moments $\mu_{k}$ are defined by

$$
\mu_{k}=\int_{0}^{\infty} x^{k} f(x) d x, k-0,1, \ldots, k,
$$


find a positive continuous function $f_{K}(x)$ such that its first $K+1$ moments are the $\mu^{\prime} s$, with $f_{K}(x)$ satisfying a given asymptotic condition.

Consider here only exponential decay. That is,

$$
f_{K}(x)=0\left(e^{-\alpha x}\right), x \rightarrow+\infty
$$

where $\alpha$ is a positive constant. The $\alpha$ will be determined by the solution instead of being specified. A similar determination of asymptotic parameters will occur in other asymptotic conditions.

The following theorem is obtained from Ref 2 :

Theorem A

A necessary condition for the existence of a solution of the Stieltjes moment problem

$$
\mu_{n}=\int_{0}^{\infty} t^{n} d \psi(t), n=0,1,2, \ldots
$$

is that

$$
\Delta_{n} \geq 0, \Delta_{n}^{(1)} \geq 0, n=0,1,2, \ldots
$$

In order that there exist a solution whose spectrum is not reducible to a finite set of points, it is necessary and sufficient that

$$
\Delta_{n}>0, \Delta_{n}^{(1)}>0, n=0,1,2, \ldots
$$

\section{Definition}

The spectrum of $\psi(t)$ is the set of points such that $\psi(t)$ is not constant in any neighborhood of those points.

In Theorem $A, \Delta_{n}$ and $\Delta_{n}^{(1)}$ are defined by

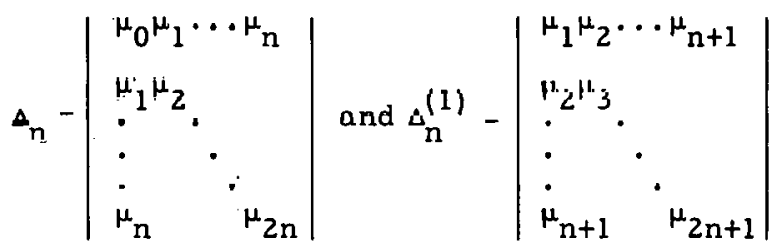

Let $S_{1}$ be the set of all positive continuous functions with finite moments. Let $S_{2}$ be the set of all functions with finite moments such that

$$
\Delta_{i}>0 \text { and } \Delta_{i}^{(1)}>0, i=0,1, \ldots, \frac{K-1}{2} .
$$

Then, the second part of Theorem A implies that $\mathrm{S}_{1} \subset \mathrm{S}_{2}$. Thus, if a given set of $\mathrm{K}+1 \mathrm{moments}$ does not satisfy (7), it is clear that no positive continuous function exists with these moments as its first $\mathrm{K}+1$ moments. However, even though (7) is satisfied, this does not imply that the moments came from a positive continuous function.

By the discussion of continued fractions in Ref 3, it can be shown that if (7) is satisfied, there exists an $\Omega_{K}(x)$, such that

$$
\Omega_{\mathrm{K}}(\mathrm{x})=\sum_{\mathrm{k}=1}^{\frac{\mathrm{K}+1}{2}} \lambda_{\mathrm{k}} \delta\left(\mathrm{x}-\beta_{\mathrm{k}}\right) \ldots
$$


where $\delta$ is the Dirac delta function, the $\lambda^{\prime}$ s are positive, and the $\beta^{\prime}$ s are both positive and distinct, with $\Omega_{\mathrm{K}}(\mathrm{x})$ satisfying (1).

For the sake of notation, it shall now be assumed that $\Omega_{K}(x)$ has moments $w_{k}, k=0,1, \ldots$, with $\Delta_{i}$ and $\Delta_{i}^{(1)}$ replaced by $W_{i}$ and $W_{i}^{(1)}$, respectively. Let $s(x)$ be a positive continuous function with moments $\sigma_{k}, k=0,1, \ldots$. Then, formally from Ref 3 ,

$$
\begin{aligned}
\sigma_{k} w_{k} & =\int_{0}^{\infty} z^{k} s(z) d z \int_{0}^{\infty} x^{k} \Omega_{K}(x) d x \\
& =\int_{z=0}^{z=\infty} \int_{x=0}^{x=\infty}(z x)^{k} s(z) \Omega_{K}(x) d x d z \\
& =\int_{u=0}^{u=\infty} \int_{x=0}^{x=\infty} u^{k} s\left(\frac{u}{x}\right) \Omega_{K}(x) \frac{d x}{x} d u .
\end{aligned}
$$

Thus, as in Ref 3, if

$$
f_{K}(z)=\int_{0}^{\infty} s\left(\frac{z}{x}\right) \Omega_{K}(x) \frac{d x}{x}
$$

and this integral converges, then

$$
\mu_{k}=\sigma_{k} w_{k}
$$

Let $s(x)$ have the desired asymptotic form. With $\mu_{k}$ given and $\sigma_{k}$ known, $k=0,1, \ldots, K$, then

$$
w_{k}=\frac{u_{k}}{\sigma_{k}} \text {. }
$$

If (7) is satisfied and all of the $\sigma_{k}$ are close enough to 1 , then, by continuity,

$$
\mathrm{w}_{\mathrm{i}}>0 \text { and } \mathrm{w}_{\mathrm{i}}^{(1)}>0, \mathrm{i}=0,1, \ldots, \frac{\mathrm{k}-1}{2} \text {. }
$$

Then, $\Omega_{\mathrm{K}}(x)$ can be represented as in (8); and (10) does converge. Thus, combining (8) and (10), .

$$
f_{K}(x)=\sum_{k=1}^{\frac{K+1}{2}} \frac{\lambda_{k}}{\beta_{k}} s\left(\frac{x}{\beta_{k}}\right) \text {. }
$$

Next, an $s(x)$ will be shown with the desired properties. The $s(x)$ must satisfy the asymptotic condition-exponential decay in this case. Also, $s(x)$ must be a positive continuous function, with some parameter present such that all its moments equal one in the limit. One such possible function is

$$
g_{n}(x, b)=S_{n}(b)[x+a]^{n} e^{-n b x}, \begin{aligned}
& x \geq 0 \\
& 0<b \leq 1
\end{aligned}
$$

where

$$
a=\frac{1-b}{b}
$$

and

$$
\frac{1}{S_{n}(b)}=\int_{0}^{\infty}[x+a]^{n} e^{-n b x_{d x}}
$$


The purpose of introducing the parameter $b$ is to allow some flexibility in the value of $g_{n}(x, b)$ at $\mathbf{x}=0$.

Let $\mathrm{m}_{\mathrm{k}, \mathrm{n}}$ be the $\mathrm{k}^{\text {th }}$ moment of $\mathrm{g}_{\mathrm{n}}(\mathrm{x}, \mathrm{b})$. Then, clearly.

$$
\mathrm{m}_{0, \mathrm{n}}=1
$$

It is obvious that $g_{n}(x, b)$ is a positive continuous function of $x$. All that remains is to show that

$$
\lim _{n \rightarrow \infty} m_{k, n}=1, k \geq 1
$$

It is easily seen that $g_{n}\left(x\right.$, b) has a maximum only at $x=1$. Since $g_{n}(x, b)$ is the $n$th power of $g_{1}(x, b)$, normalized such that (18) is satisfied; then from geometrical considerations

$$
\lim _{n \rightarrow \infty} g_{n}(x, b)=\delta(x-1) \text {. }
$$

Thus, (19) is satisfied.

Since the values of $m_{k, n}$ will be needed in computations, their form will be derived now.

First, using the Binomial Theorem on (15),

$$
g_{n}(x, b)=s_{n}(b) \sum_{i=0}^{n} a^{i} x^{n-i} \frac{n !}{i !(n-i) !} e^{-n b x}
$$

Since

$$
\int_{0}^{\infty} x^{n-i} e^{-n b x} d x=\frac{(n-i) !}{(n b)^{n-i+1}}
$$

then

and

$$
\frac{1}{S_{n}(b)}=\frac{n !}{(n b)^{n+1}} \sum_{i=0}^{n}\left[\frac{n(1-b)}{i !}\right]^{i}
$$

$$
m_{k, n}=\frac{n !}{(n b)^{n+1}} s_{n}(b) \sum_{i=0}^{n}\left[\frac{n(1-b)}{i !}\right]^{i} \prod_{r=1}^{k}\left[\frac{n+r-i}{n b}\right], k \geq 1 .
$$

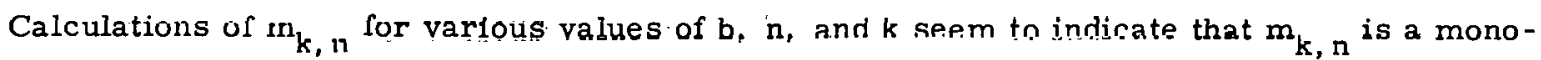
tonically decreasing function of $b$ as $b$ approaches one. Also, the calculations seem to indicate that $\mathrm{m}_{\mathrm{k}, \mathrm{n}}$ is a monotonically decreasing function of $\mathrm{n}$ for any $\mathrm{b}$ in the range $0<\mathrm{b} \leq 1$.

All that remains is to outline the calculation of the $\lambda^{\prime}$ s and $\beta$ 's introduced in (8). First, the following theorem is taken from Ref 4 :

\section{Theorem B}

If the set of polynomials

$$
P_{n}(x)=\sum_{j=0}^{n} a_{n, j} x^{j}, n=0, \ldots, \frac{K+1}{2}
$$

is formed such that 


$$
\int_{0}^{\infty} P_{n}(x) P_{m}(x) \Omega_{K}(x) d x=\left\{\begin{array}{r}
0, m \neq n \\
\neq 0, m=n
\end{array}\right.
$$

where $\Omega_{\mathrm{K}}(\mathrm{x})$ is non-negative in $0 \leq \mathrm{x}<\infty$, then $\mathrm{P}_{\frac{\mathrm{K}+1}{2}}(\mathrm{x})$ has exactly $\frac{\mathrm{K}+1}{2}$ distinct zeros, all of which are real and lie in the interval 0 to $\infty$.

In order to construct $P_{\frac{K+1}{2}}$ (x) up to an arbit rary constant, let

$$
\int_{0}^{\infty} \mathrm{x}^{l} \mathrm{P}_{\frac{\mathrm{K}+1}{2}}(\mathrm{x}) \Omega_{\mathrm{K}}(\mathrm{x}) \mathrm{dx}=0, \ell=0,1, \ldots, \frac{\mathrm{K}-1}{2}
$$

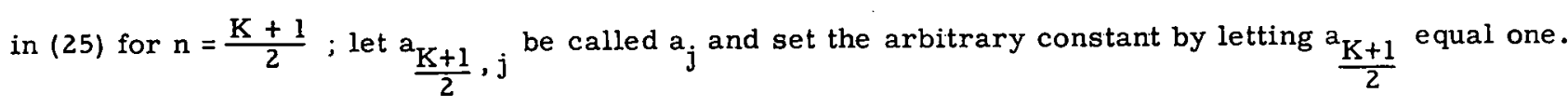
Then (27) yields:

$$
\begin{gathered}
w_{0} a_{0}+w_{1} a_{1}+\ldots+w_{\frac{K-1}{2}} a_{\frac{K-1}{2}}=-w_{\frac{K+1}{2}}, \\
w_{1} a_{0}+w_{2} a_{1}+\ldots+w_{\frac{K+1}{2}} a_{\frac{K-1}{2}}=-w_{\frac{K+3}{2}} \\
\vdots \\
\vdots \\
w_{\frac{K-1}{2}} a_{0}+w_{\frac{K+1}{2}} a_{1}+\ldots+w_{K-1} a_{\frac{K-1}{2}}=-w_{K}
\end{gathered}
$$

Since $\mathrm{W}_{\frac{\mathrm{K}-1}{2}} \neq 0$ by (13), (28) can be solved for the a's. Thus,

$$
P_{\frac{K+1}{2}}=\sum_{j=0}^{\frac{K+1}{2}} a_{j} x^{j}
$$

Now, consider a theorem from Ref 3.

Theorem C $\underset{2}{K+1}$, Euch that

$$
\int_{0}^{\infty} P(x) \Omega_{K}(x) d x=\sum_{i=1}^{\frac{K+1}{2}} \lambda_{i} P\left(\beta_{i}\right),
$$

where $\Omega_{\mathrm{K}}(\mathrm{x})$ is defined as previously, and the $\beta_{i}$ are defined as the zeros of the $\frac{\mathrm{K}+1}{2}$ th orthogonal polynomial $\mathrm{P}_{\frac{\mathrm{K}+1}{2}}(\mathrm{x})$, with respect to $\Omega_{\mathrm{K}}(\mathrm{x})$. That is,

$$
P_{\frac{K+1}{2}}\left(\beta_{i}\right)=0 ; i=1, \ldots, \frac{K+1}{2}
$$

defines the set of $\beta_{\mathbf{i}},\left(\beta_{1}<\beta_{2}<\ldots<\beta_{\mathbf{n}}\right)$.

By Theorem $C$ there exists a set of positive $\lambda$ 's such that

$$
w_{k}=\int_{0}^{\infty} x^{k} \Omega_{K}(x) d x=\sum_{i=1}^{\frac{K+1}{2}} \lambda_{i} \beta_{i}^{k}, k=0,1, \ldots, \frac{K-1}{2} \text {. }
$$


This set of equations can be solved for the $\lambda$ 's. Q.E.D.

\section{THE HAMBURGER MOMENT PROBLEM}

As in the Stieltjes moment problem, given an even number of moments of an unknown positive continuous function $f(x)$, say $K+1$, and that the moments $\mu_{k}$ are defined by

$$
\mu_{k}=\int_{-\infty}^{\infty} x^{k} f(x) d x, k=0,1, \ldots, k
$$

find a positive continuous function $f_{K}(x)$ such that its first $K+1$ moments are the $\mu_{k}$, with $f_{K}(x)$ satisfying two given asymptotic conditions. Consider here only exponential decay. That is,

$$
f_{K}(x)=0\left(e^{-\alpha_{1} x}\right), x \rightarrow+\infty
$$

and

$$
f_{K}(x)=0\left(e^{\alpha}\right), x \rightarrow-\infty
$$

where $\alpha_{1}$ and $\alpha_{2}$ are positive constants determined by the solution. As in the Stieltjes case, a similar determination of asymptotic parameters would occur in other asymptotic conditions.

The following theorem is taken from Ref 2 :

\section{Theorem A'}

In order that a Hamburger moment problem

$$
\mu_{n}=\int_{-\infty}^{\infty} t^{n} d \psi(t), n=0,1,2, \ldots
$$

shall have a solution, it is necessary that

$$
\Delta_{\mathrm{n}} \geq 0,1,2, \ldots .
$$

In order that there exist a solution whose spectrum is not reducible to a finite set of points, it is necessary and sufficient that

$$
\Delta_{n}>0, n=0,1, \quad, \ldots, \ldots
$$

In $(36)$ and $(37), \Delta_{\mathrm{in}}$ is as in $(6)$.

Let $S_{1}$ be the set of all positive continuous functions with finite moments. Let $S_{2}$ be the set of all functions with finite moments such that

$$
\Delta_{i}>0, i=0,1, \ldots, \frac{K-1}{2} .
$$

Then, the second part of Theorem $A^{\prime}$ implies that $S_{1} \subset S_{2}$.

Thus, if a given set of $\mathrm{K}+1$ moments does not satisfy (38), it is clear that no positive continuous function exists with those moments as its first $K+1$ moments. However, even if (38) is satisfied, this does not imply that the moments came from a positive continuous function.

Next, from a modification of the equivalent point distributions discussion in Ref 5 , it may be concluded that if (38) is satisfied, there exists an $\Omega_{\mathrm{K}}(\mathrm{x})$ such that

$$
\Omega_{K}(x)=\sum_{k=1}^{\frac{K+1}{2}} \lambda_{k} \delta\left(x-\beta_{k}\right),
$$


where the $\lambda^{\prime}$ s are positive and the $\beta^{\prime}$ 's are both real and distinct, with $\Omega_{\mathrm{K}}$ (x). satisfying (33). The modifications in Ref 5 consist of the following:

The equation

$$
\sum_{\alpha=1}^{n+1} A_{\alpha} \xi_{\alpha}^{2 n+1}=m_{2 n+1}
$$

is added to system (A), defined in Ref 5: Then $\theta(x)^{*}$ is of degree $n$, and it can be shown that

$$
Q(x)=\left(\alpha_{n+1} x+\beta_{n+1}\right) Q_{n}(x)-Q_{n-1}(x)
$$

The rest of the proof continues as in Ref 5 .

Now, it shall be assumed again that $\Omega_{K}(x)$ has moments $w_{k}, k=0,1, \ldots$, with $\Delta_{i}$ replaced by $\mathrm{w}_{\mathrm{i}}$. Let $\mathrm{s}(\mathrm{x})$ be a positive continuous function with moments $\sigma_{k}$ ' $k=0,1, \ldots$. Then formally,

$$
\begin{aligned}
\sigma_{k} w_{k} & =\int_{-\infty}^{\infty} z^{k} s(z) d z \int_{-\infty}^{\infty} x^{k} \Omega_{K}(x) d x \\
& =\int_{z=\infty}^{z=\infty} \int_{x=-\infty}^{x=\infty}(z x)^{k} s(z) \Omega_{K}(x) d x d z \\
& =\int_{u=-\infty}^{u=\infty} \int_{x=0}^{x=\infty} u^{k} s\left(\frac{u}{x}\right) \Omega_{K}(x) \frac{d x}{x} d u+\int_{u=\infty}^{u=\infty} \int_{x=-\infty}^{x=0} u^{k} s\left(\frac{u}{x}\right) \Omega_{K}(x) \frac{d x}{x} d u \\
& =\int_{u=-\infty}^{u=\infty} \int_{x=-\infty} u^{k} s\left(\frac{u}{x}\right) \Omega_{K}(x) \frac{d x}{|x|} .
\end{aligned}
$$

Thus, if

$$
f_{K}(x)=\int_{-\infty}^{\infty} s\left(\frac{z}{x}\right) \Omega_{K}(x) \frac{d x}{|x|}
$$

and this integral converges, then

$$
\mu_{k}=\sigma_{k} w_{k}
$$

Let $s(x)$ have the desired asymptotic forms. Then, with $\mu_{k}$ given and $\sigma_{k}$ known, $k=0,1, \ldots, K$,

$$
w_{k}=\frac{\mu_{k}}{\sigma_{k}}, k=0,1, \ldots, \quad k
$$

If (38) is satisfied and all of the $\sigma_{k}$ are close enough to 1 , then by continuity

$$
\mathrm{w}_{\mathrm{i}}>0, \mathrm{i}=0,1, \ldots, \frac{\mathrm{K}-1}{2}
$$

It follows that $\Omega_{\mathrm{K}}(\mathrm{x})$ can be represented as in (39); and (43) does converge. Thus, combining (39) and (43),

$$
f_{K}(x)=\sum_{k=1}^{\frac{K+1}{2}} \frac{\lambda_{k}}{\left|\bar{\beta}_{k}\right|} s\left(\frac{x}{\bar{\beta}_{k}}\right) .
$$

* See page 370 of Ref 5 . 
Next, a choice function will be shown with the desired properties. The function must satisfy the asymptotic conditions-exponential decay in this case. Also, it must be a positive continuous function, with some parameter present such that all its moments equal one in the limit. One such possible function, where $0<b<1$, is

and

$$
g_{n}(x, b)=s_{n}(b)\{x+a]^{n} e^{-n b x}, x \geq 0
$$

$$
g_{n}(x, b)=S_{n}(b)[a-x]^{n} e^{\frac{n x}{a}}, x<0,
$$

where $a=\frac{1-b}{b}$, and

$$
\frac{1}{S_{n}(b)}=\int_{-\infty}^{0}[a-x]^{n} e^{\frac{n x}{a}} d x+\int_{u}^{\infty}[x+a]^{n} e^{-n b x} d x
$$

Let $m_{k, n}$ be the $k^{\text {th }}$ moment of $g_{n}(x, b)$. Then, clearly

$$
m_{0, n}=1 \text {. }
$$

It is obvious that $g_{n}(x, b)$ is a positive continuous function of $x$, so all that remains is to show that

$$
\lim _{n \rightarrow \infty} m_{k, n}=1, k \geq 1 \text {. }
$$

It is easily seen that $g_{1}(x, b)$ has a maximum only at $x=1$. Since $g_{n}(x, b)$ is the $n^{\text {th }}$ power of $g_{1}(x, b)$, normalized such that $(50)$ is satisfied, then, from geometrical considerations

$$
\lim _{n \rightarrow \infty} g_{n}(x, b)=\delta(x-1)
$$

Thus, (5l) is satisfied.

Now, the form of $m_{k, n}$ will be derived. First, using the Binomial Theorem on (48),

$$
g_{11}(x, b)=S_{11}(b) \quad \sum_{i=0}^{n} a^{i} x^{n-1} \frac{n !}{i !(11-i) !} e^{-n b x}, x \geq 0
$$

and

$$
g_{n}(x, b)=S_{n}(b) \sum_{i=0}^{n} a^{i}(-x)^{n-i} \frac{n !}{i !(n-i) !} e^{\frac{n x}{a}}, x<0
$$

After extensive arithmetical calculation, it can be shown that

$$
m_{k, n}=\sum_{i=0}^{n} c_{k, i} \prod_{r=1}^{k}\left[1+\frac{r-1}{n}\right] \text {, }
$$

where

$$
c_{k, i}=\frac{s_{n}(b) n !(n a)^{i}}{n^{n+1} i ! b^{n+k+1-i}}\left[1+(-1)^{k}(1-b)^{n+k+1-i}\right] .
$$

Also,

$$
\frac{1}{S_{n}(b)}=\sum_{i=0}^{n} c_{0, i} .
$$


All that remains is to outline the calculation of the $\lambda^{\prime}$ 's and $\beta^{\prime}$ 's introduced in (47). First, the following theorem is taken from Ref 4:

\section{Theorem B'}

If the set of polynomials

$$
P_{n}(x)=\sum_{j=0}^{n} a_{n, j} x^{j}, n=0,1, \ldots, \frac{K+I}{2}
$$

is formed such that

$$
\int_{-\infty}^{\infty} P_{n}(x) P_{m}(x) \Omega_{K}(x) d x=\left\{\begin{array}{cc}
0, & m \neq n \\
\neq 0, & m=n
\end{array},\right.
$$

where $\Omega_{K}(x)$ is non-negative, then $P_{\frac{K+1}{2}}(x)$ has exactly $\frac{K+1}{2}$ distinct real zeros.

In order to construct $P_{\frac{K+1}{2}}(x)$, up to an arbitrary constant, let

$$
\int_{-\infty}^{\infty} x^{\ell} P_{K+1}(x) \Omega_{K}(x) d x=0, \ell=0,1, \ldots, \frac{K-1}{2} .
$$

In (57) for $n=\frac{K+1}{2}$, let $\frac{a_{K+1}}{2}, j$ be called $a_{j}$ and set the arbitrary constant by letting $\frac{a_{K+1}}{2}$ equal one. Then (58) yields (28). Since $\frac{\mathrm{W}_{\frac{K-1}{2}}}{2} \neq 0$ by (46), (28) can be solved for the a's. Thus, (29) is obtained.

Now, consider a theorem from Ref 3.

Theorem $\mathrm{C}^{\prime}$

Given a polynomial $P(x)$ of degree $K$ or less, there exists a set of positive $\lambda_{i}, i=1, \ldots, \frac{K+1}{2}$, such that

$$
\int_{-\infty}^{\infty} P(x) \Omega_{K}(x) d x=\sum_{i=1}^{\frac{K+1}{2}} \lambda_{i} P\left(\beta_{i}\right)
$$

where $\Omega_{K}(x)$ is defined as previously shown, and the $\beta^{\prime}$ s are defined to be the zeros of the $\left(\frac{K+1}{2}\right)^{\text {th }}$ orthogonal polynomial $\frac{\mathrm{P}_{\frac{\mathrm{K}+l}{2}}}{2}(\mathrm{x})$ with respect to $\Omega_{\mathrm{K}}(\mathrm{x})$. That is,

$$
\mathrm{P}_{\frac{\mathrm{K}+1}{2}}\left(\beta_{\mathrm{i}}\right)=0, \mathrm{i}=1, \ldots, \frac{\mathrm{K}+\mathrm{l}}{2}
$$

defines the set of $\beta_{i}$ where $\left(\beta_{1}<\beta_{2}<\ldots<\beta_{n}\right)$.

By Theorem C' there exists a set of positive $\lambda$ 's such that

$$
w_{k}=\int_{-\infty}^{\infty} x^{k} \Omega_{K}(x) d x=\sum_{i=1}^{\frac{K+1}{2}} \lambda_{i} \beta_{i}^{k}, k=0,1, \ldots, \frac{K-1}{2} .
$$

This set of equations can be solved for the $\lambda^{\prime}$ s. Q.E.D. 
The computer solution of the Stieltjes moment problem is accomplished as follows:

1) $\mathrm{K}$ and $\mu_{\mathrm{k}}$ are given, $\mathrm{k}=0,1, \ldots, \mathrm{K}$.

2) Check that $\mathrm{K}$ is odd. If not, indicate the error.

3) Check that (7) is satisfied. This can be done as a by-product of Gauss elimination. That is, consider the evaluation of $\frac{\Delta_{\mathrm{K}-1}}{2}$ by triangulation. After the $i^{\text {th }}$ step, $\Delta_{i}$ is simply the product of the first $i+1$ terms along the main diagonal. Thus, if $\frac{\Delta_{K-1}}{2}$ is triangulated and all of the diagonal elements are positive, then

$$
\Delta_{i}>0, i=0,1, \ldots, \frac{K-1}{2} \text {. }
$$

A similar calculation can be performed to verify the second portion of (7). If (7) is not satisfied, the $\mu$ 's do not come from a positive continuous function, therefore, no solution is possible. If no solution is possible, indicate the identification of the first determinant to fail the test.

4) Set $n$ equal to one. The value of $b$ in $g_{n}(x, b)$ will be assumed to be fixed in the program.

5) Compute $m_{k, n}, k=0,1, \ldots, k$.

6) Compute

$$
w_{k, n}=\frac{\mu_{k}}{m_{k, n}}, k=0,1, \ldots, k
$$

7) Test to see if (13) is satisfied, using the scheme in step 3. If so, go to step 8 . If not, compare $n$ with $L$, the largest value of $n$ to be permitted (fixed in the program). If $n$ is less than $L$, increase $n$ by one and go to step 5 . If $n$ equals. $L$, indicate the identification of the first determinant to fail the test.

8) Solve (28) for the a's. A unique solution is assured by step 7 .

9) Find all of the zeros of $(\angle y)$. 'Ihe successful testing In slep 7 assuiles llial the $\rho$ 's are positive and distinct.

10) Solve (32) for the $\lambda^{\prime}$ 's. The successful testing in step 7 not only guarantees a unique solution, but guarantees that the $\lambda^{\prime}$ s are positive.

1i) Given values of $x$ for which $f_{K}(x)$ is to be évaluated, apply (14) where $s(y)$ is $g_{n}(y, u)$.

\section{COMPUTER SOLUTION OF THE HAMBURGER MOMEN'T PROBLEM}

The computer solution of the Hamburger moment problem is accomplished as follows:

1) $\mathrm{K}$ and $\mu_{\mathrm{k}}$ are given, $\mathrm{k}=0,1, \ldots \mathrm{K}$.

2) Check that $K$ is odd. If not, indicate the error.

3) Check that (38) is satisfied, using the scheme in step 3 of the previous section on the computer solution of the Stieltjes moment problem. If $(38)$ is not satisfied, the $\mu$ 's do not come from a positive continuous function, thus no solution is possible. If no solution is possible, indicate the identification of the first determinant to fail the test.

4) Set $n$ equal to one. The value of $b$ in $g_{n}(x, b)$ will be assumed to be fixed in the program.

5) Compute $m_{k, n}, k=0,1, \ldots, K$.

6) Compute

$$
w_{k, n}=\frac{\mu_{k}}{m_{k, n}}, k=0,1, \ldots, k
$$


7) Test to see if (46) is satisfied, using the scheme in step 3 of this section. If so, go to step 8 . If not, compare $n$ with $L$, the largest value of $n$ to be permitted (fixed in the program). If $\mathrm{n}$ is less than $\mathrm{L}$, increase $\mathrm{n}$ by one and go to step 5 . If $\mathrm{n}$ equals $\mathrm{L}$, indicate the.identification of the first determinant to fail the test.

8) Solve (28) for the a's. A unique solution is assured by step 7 .

9) Find all the zeros of (29). The successful testing in step 7 insures that the $\beta^{\prime}$ s are real and distinct.

10) Solve (32) for the $\lambda^{\prime}$ s. The successful testing in step 7 not only guarantees a unique solution, but guarantees that the $\lambda$ 's are positive.

11) Given values of $x$ for which $f_{K}(x)$ is to be evaluated, apply (47) where $s(y)$ is $g_{n}(y, b)$.

\section{NUMERICAL RESULTS}

The computer solution of the Stieltjes problem was programmed for the IBM -650 , using the Bell Laboratory Interpretive System. The test problem used was the same one as in Ref 3 , namely

$$
f(x)=2.4777 \frac{x}{x+1} e^{-x}, x \geq 0
$$

Then, with $\mu_{k}$ being the $k^{\text {th }}$ moment of $f(x)$, it can be shown that $\mu_{0}$ is one and

$$
\mu_{\mathrm{k}}=2.4777 \mathrm{k} !-\mu_{\mathrm{k}-1}, \mathrm{k}=1,2, \ldots
$$

With $\mathrm{b}$ equal to one, for $\mathrm{K}$ equal to five, $\mathrm{n}$ was one; therefore, the solution was simply Spencer's method. For $\mathrm{K}$ equal to seven, however, $\mathrm{n}$ was two. The following results were obtained:

$\begin{array}{llll}\mathbf{x} & & \frac{f_{5}(x)}{f(x)} & \frac{f_{7}(x)}{f(x)} \\ 0.1 & 0.1992 & \frac{f(x)}{0.977} & 0.794 \\ 0.2 & 0.3342 & 0.989 & 1.059 \\ 0.3 & 0.4219 & 0.996 & 1.102 \\ 0.4 & 0.4750 & 1.001 & 1.070 \\ 0.5 & 0.5028 & 1.004 & 1.026 \\ 0.6 & 0.5125 & 1.005 & 0.992 \\ 0.7 & 0.5094 & 1.006 & 0.973 \\ 0.8 & 0.4973 & 1.005 & 0.967 \\ 0.9 & 0.4792 & 1.004 & 0.969 \\ 1.0 & 0.4573 & 1.003 & 0.976 \\ 1.1 & 0.4330 & 1.002 & 0.985 \\ 1.2 & 0.4075 & 1.001 & 0.993 \\ 1.3 & 0.3817 & 1.000 & 1.000 \\ 1.4 & 0.3561 & 0.999 & 1.005 \\ 1.5 & 0.3312 & 0.998 & 1.010 \\ 1.6 & 0.3072 & 0.998 & 1.012 \\ 1.7 & 0.2842 & 0.997 & 1.013 \\ 1.8 & 0.2625 & 0.997 & 1.012 \\ 1.9 & 0.2420 & 0.997 & 1.011 \\ 2.0 & 0.2229 & 0.997 & 1.010 \\ 3.0 & 0.0926 & 1.000 & 0.994 \\ 4.0 & 0.0364 & 1.003 & 0.998 \\ 5.0 & 0.0139 & 1.001 & 1.004 \\ 6.0 & 0.0053 & 0.998 & 1.003 \\ 7.0 & 0.0020 & 0.996 & 0.999 \\ 8.0 & 0.0007 & 0.996 & 0.995 \\ 9.0 & 0.0003 & 0.998 & 0.996 \\ 10.0 & 0.0001 & 1.002 & 0.999\end{array}$

In this particular case, the solution for eight moments differed from the true solution more than the solution for six moments. In fact, this was the situation in most problems that were run. One. 
exception to this was

$$
f(x)=\frac{a^{\alpha}}{\Gamma(\alpha)} x^{\alpha-1} e^{-a x}
$$

where $\Gamma(\alpha)$ is the Gamma function and $a=\alpha=10$. With $b$ equal to one, $\mathrm{n}$ was ten for $\mathrm{K}$ equal to both five and seven. The following results were obtained:

$\begin{array}{llll}\frac{f}{x} & & \frac{f_{5}(x)}{f(x)} & \frac{f_{7}(x)}{f(x)} \\ 0.2 & 0.0020 & \frac{0.889}{0.932} & 1.001 \\ 0.4 & 0.1323 & 1.003 & 1.000 \\ 0.6 & 0.6884 & 1.000 & 1.000 \\ 0.8 & 1.2410 & 0.999 & 1.000 \\ 1.0 & 1.2510 & 1.001 & 1.000 \\ 1.2 & 0.8736 & 1.000 & 1.000 \\ 1.4 & 0.4734 & 1.000 & 1.000 \\ 1.6 & 0.2131 & 1.000 & 1.000 \\ 1.8 & 0.0833 & 1.000 & 1.000 \\ 2.0 & 0.0291 & 1.001 & 1.000 \\ 2.4 & 0.0275 & 1.001 & 1.000 \\ 2.8 & 0.0002 & 0.995 & 1.001 \\ 3.0 & 0.0001 & 0.989 & \end{array}$

Parrette (Ref 6) had the asymptotic condition of the Stieltjes program altered so that the function $s(x)$ was of exponential decay of order 2 (Ref 7). One of Parrette's test problems was:

$$
f(x)=\frac{1}{2 \pi \sigma d} e^{-\frac{\left(x-\frac{1}{d}-1\right.}{u^{2}}} x^{2}-\left(\frac{1}{d}+1\right)
$$

with $d=1.65$ and $\sigma=0.04529$. This problem was run on both programs. For the program described in this paper, with $b$ equal to one, $n$ was 224 . The following results were obtained:

$\begin{array}{lccc}\frac{f}{x} & \frac{f(x)}{1.0} & \frac{f_{g}(x)}{f(x)} \text {, order 2 } & \frac{f_{5}(x)}{f(x)} \\ 1.1 & 2.3381 & 0.994 & 1.008 \\ 1.2 & 0.0926 & 1.024 & 0.981 \\ 1.3 & 0.2744 & 1.115 & 1.065 \\ 1.4 & 0.0184 & 3.186 & 0.864 \\ & 0.0007 & 0.020 & 0.373\end{array}$

The methods presented in this report are useful when an estimate of the unknown function is desired. The asymptotic conditions can be changed will lelative ease, and the mothods are highly applicable to digital computers.

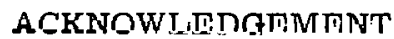

The author is indebted to Dr. Richard S. Varga, whose criticisms were most helpful in the preparation of this report.

\section{REFERENCES}

1. L. V. Spencer, "Penetration and Diffusion of X-Rays: Mathematical Techniques, "National Bureau of Standards Report 1442, (March 4, 1952).

2. J. A. Shohat and J. D. Tamarkin, The Problem of Moments, American Mathematical Society, (1950), pp 5,6. 
3. R. S. Varga and J. S. Langer, "The Problem of Moments with Application to Neutron Flux Distributions, "Bettis Atomic Power Division Report WAPD-TN-520, (Nov. 1955), pp 8, $10,28$.

4. G. Szegö, Orthogonal Polynomials, (New York: American Mathematical Society Colloquium Publications, 1939, Vol. XXIII), p 43.

5. J. V. Uspensky, Introduction to Mathematical Probability, lst Ed., (New York: McGraw-Hill, 1937), p 369.

6. J. R. Parrette, "Frequency Functions of Products of Randomly Distributed Variables, " Bettis Atomic Power Division Technical Paper WAPD-T-971, to be published.

7. E. C. Titchmarsh, The Theory of Functions, 2nd Ed., (London: Oxford University Press, 1939), p 248 . 